\title{
Studies on the chronic phase of adjuvant arthritis: effect of SR 41319, a new diphosphonate
}

\author{
A BARBIER, J C BRELIËR, B REMANDET, AND R RONCUCCI \\ From Sanofi Research, Clin-Midy Research Center, Avenue du Pr J Blayac, Montpellier, France
}

SUMMARY We studied the course of adjuvant arthritis in rats by measuring clinical, biochemical, and histological parameters on day 36 after induction (representing the secondary reaction) and on day 171 , which is at the stage of permanent deformity. The effect of SR 41319 , a new diphosphonate, was evaluated on days 36 and 171, after three weeks of treatment (days 14-35 inclusive). In the absence of treatment all the measured parameters were markedly abnormal on day 36 , indicating the presence of lesions that were still evolving. On day 171 clinical parameters and the lesion histological index remained the same, whereas the biochemical parameters and disease activity histological index had returned to normal, indicating that the lesions at this stage although severe were not inflammatory and consequently not progressing. SR 41319 treatment reduced the severity and progression of the disease both on day 36 and on day 171 . We conclude that SR 41319 may be a potentially useful drug for the treatment of rheumatoid arthritis.

Key words: chronic disease, experimental model, anti-inflammatory agents.

Rheumatoid arthritis is a chronic inflammatory disease of joints resulting in cartilage and bone destruction by proliferating synovial tissue. As the evolution of the disease shows periods of exacerbation of inflammatory symptoms, the search for drugs to treat rheumatoid arthritis has been directed mostly against inflammation, leading to the introduction of non-steroidal anti-inflammatory drugs (NSAIDs). Clinical evidence, however, has shown that although NSAIDs are effective inhibitors of inflammatory symptoms, they do not influence the erosive process. ${ }^{1}$ We speculated that new agents directed at the rheumatoid process itself might limit cartilage and bone erosion. To test such agents we have therefore developed a model of rat adjuvant arthritis which exhibits a prolonged phase of chronic inflammation associated with severe tissue injury (and bone remodelling), and in the present paper we describe the evolution of the disease over a period of nearly six months, while monitoring several clinical, biochemical, and histological parameters. This model has been used to assess the effects of a three-week treatment with a new potentially antiarthritic diphosphonate, ${ }^{2}$ SR 41319, (4-chlorophenyl) thio methylene diphosphonic acid.

Accepted for publication 19 June 1985.

Correspondence to $\operatorname{Dr}$ A Barbier, Centre de Recherches, Clin-Midy, Avenue du Pr J Blayac, Montpellier, France.

\section{Materials and methods}

ANIMALS

Seventy adult male COBS CD rats from Charles River (France) weighing $160 \pm 10$ (SEM) $g$ at the beginning of the experiment were used.

\section{A RT H R I T IS}

Arthritis was induced by intradermal injection of $0 \cdot 4$ mg of heat killed, dried Mycobacterium tuberculosis (Difco Laboratories, Inc., Detroit, MI) in $0.05 \mathrm{ml}$ of sterile paraffin oil into the base of the tail of 60 rats. Ten rats acted as controls. The day of adjuvant injection was designated day 0 . Disease intensity was assessed 14 days after adjuvant inoculation by means of a polyarthritis index (PI:see below). In order to minimise the possibility of including animals with minimal transient disease only rats with a PI of 6 or more were included; these were randomly assigned to two groups of 14 animals. Seven animals from each group were killed on day 36 and the remainder on day 171 .

\section{DRUG TREATMENT}

Animals of group 2 received SR $41319 \quad(0 \cdot 16$ $\mathrm{mmol} / \mathrm{kg}$ in water at $\mathrm{pH} \mathrm{7)}$ orally every day from day 14 to day 35, except Sundays. Control animals (group 1) received only the vehicle. 
EVA L U A T I O N

Development of arthritis was monitored by means of the following clinical, histological, and biochemical parameters.

The polyarthritis index $(P I)$, ranging from 0 to 12 , was scored for each rat twice weekly from day 14 to day 35 and once weekly thereafter by the same person. Both hind paws were graded separately from 0 to 3 , depending on the severity of redness, swelling, and ankylosis; both forelegs separately from 0 to 2, depending on swelling and ankylosis; both ears separately from 0 to 1 , depending on the presence of vascular lesions.

The volume of the right hind paw was measured with an electronic water plethysmometer (Ugo Basile) on the same days as the PI assessment.

Grip strength was measured by the ability of rats to remain on a rotating rod for 30 seconds. Four tests were performed at five minute intervals the day before sacrifice, after training twice a week throughout the experiment. The results were expressed as the mean time the rat remained on the rod.

$X$-ray analysis was performed with a Philips Oralix dental apparatus. The exposure time was 0.4 second on Kodak dental $x$-ray film (DF $5057 \times 76$ $\mathrm{mm})$. The rats were lightly anaesthetised with ether, and the right hind paw was $x$-rayed with a $90^{\circ}$ projection from the medial aspect. Lesions were assessed by allocating a score (radiological index; $\mathrm{RI}$ ), ranging from 0 to 4 , as follows: 0 , no lesion; 1 , slight osteoporosis and oedema; 2 , reduction of joint spaces; 3, marked lesions of bone and cartilage with gross reduction of joint spaces; 4 , disappearance of joint structure, osteophytes, calcification.

Histological analysis was performed on day 36 and day 171 . The rats were killed by puncture of the abdominal aorta under light ether anaesthesia. The right hind paw was amputated above the tibiotarsal joint and fixed in neutral formalin. Histological observations were made on haematoxylin-phloxin stained paraffin sections of decalcified samples (formic acid/water $/ 40 \%$ formalin; 50/45/5). The lesions and the disease activity were assessed by means of two indexes. The lesion index (LI), ranging from 0 to 4 , was scored as follows: 0 , no lesion; 1, minimal synovitis and osteophytosis (metaphysis only); 2, moderate synovitis and interstitial inflammatory reaction, moderate osteophytosis (metaphysis and diaphysis), development of early pannus on articular surface; 3 , marked synovitis and interstitial inflammatory reaction, marked osteophytosis with bone distortion, advanced articular changes with disappearance of bone joints; 4 , structures completely destroyed, no visible articulation. The disease activity index (DAI), ranging from 0 to 3 , was scored as follows: 0 , stabilised non- inflammatory lesions with fibrosis but no bone or chondrocytic activity; 1 , localised inflammatory $\overrightarrow{\vec{F}}$ reactions showing bone and chondrocytic activity; $2, \stackrel{?}{?}$ additional sites of inflammatory reaction showing bone and chondrocytic activity; 3, widespread developing lesions.

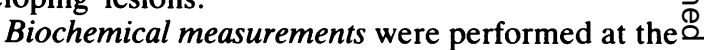
time of sacrifice: erythrocyte sedimentation rate was determined at two hours and plasma sulphydryl $\vec{\circ}$ (SH) level was spectrophotometrically assessed with Ellman's reagent ${ }^{3}$ on blood collected over sodium $\vec{\omega}$ citrate $(1 \%)$ by abdominal aorta puncture. Simultaneously, the left hind paw of each rat was cut ato the level of the tibiotarsal joint, ground in liquid of nitrogen (freezer mill SPEX), and freeze dried; the amounts of prostaglandin $\mathrm{E}_{2}\left(\mathrm{PGE}_{2}\right)$ and $\beta-N$ - -9 acetylglucosaminidase activity (NAG) in this sampleo were measured by a radioimmunoassay with Pasteur? antisera ${ }^{4}$ for $\mathrm{PGE}_{2}$ and a spectrophotometric assayc with $p$-nitrophenyl- $N$-acetyl- $\beta$-D-glucosaminide as substrate for NAG. ${ }^{5}$

STATISTICAL ANALYSIS

Student's $t$ test was used to analyse all parameterso except the polyarthritis index, the radiologicalo score, and the histological indexes, which were analysed by the Kruskal-Wallis test.

\section{Results}

TIME COURSE OF ARTHRITIS UP TO DAY $171 \frac{\overrightarrow{\mathrm{o}}}{3}$ Fig. 1a shows changes of PI for positive controls (group 1) during the observation period of 171 days after adjuvant injection. Arthritic rats showed a progressive increase of PI which peaked 24 days postadjuvant and slowly decreased thereafter buto still remained high (about 7) at the end of the experiment. The kinetics of changes in paw volumeo were somewhat different, the maximum swelling occurring on day 43 and remaining at this high levelo throughout the experiment (Fig. 1b). These clinical $\triangle$ changes were reflected in the grip strength: arthritico rats on day 35 and on day 170 were scarcely able ton remain on the rotating rod (Table 1). The kinetics of changes in the biochemical parameters (Table 2) 0 were quite different. The erythrocyte sedimentation rate, which was markedly increased on day 36, hadO almost returned to normal by day 171; similarly theo tissue content of $\mathrm{PGE}_{2}$ and $\mathrm{NAG}$, which were significantly increased on day 36 , had returned to $\stackrel{?}{?}$ normal values on day 171 , and the decrease in plasma SH level seen on day 36 did not persist up to울

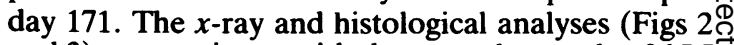
and 3) are consistent with these results: on day $36 \mathrm{LI} \stackrel{\mathbb{Q}}{\mathbb{Q}}$ and DAI were both close to their maximum levelo but, whereas the LI remained high on day 171 , no 
1 a

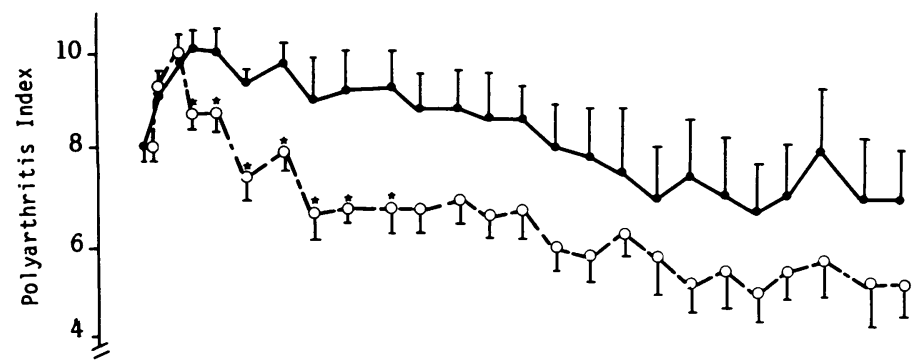

$1 \mathrm{~b}$

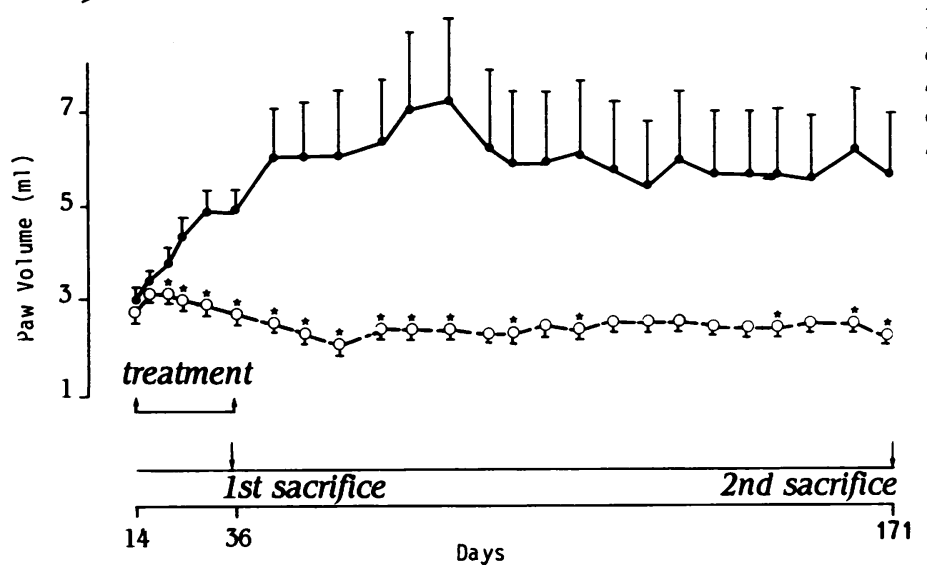

Fig. 1 Evolution of rat adjuvant arthritis: effect of three weeks' SR 41319 treatment. OArthritic controls; OSR $413190.16 \mathrm{mmol}$ $k g / d$ orally. $\delta$ Mean $\pm S E M$. ${ }^{*} p \leqslant 0.05$ versus arthritic controls.

signs of active disease were noticeable at that time (Table 3).

\section{EFFECT OF THREE WEEKS' TREATMENT WITH} SR 41319

Several different treatment schedules have previously been used in the management of rat adjuvant arthritis. However, it is generally recognised that a two to four weeks' treatment from day 14 onwards provides an index of the therapeutic value of a given drug. In a preliminary dose-ranging study with a three week treatment an oral dose of 0.16 $\mathrm{mmol} / \mathrm{kg} /$ day was shown to be the minimal active one and chosen for the experiment reported here. Compared with the positive controls oral administration of SR 41319 at this dose from day 14 to day 35 postadjuvant markedly modified the time course of the disease. As shown in Fig. 1a the PI increased for both groups from day 14 to day 24; thereafter, a rapid decrease ensued in the treated group which persisted until the end of the experiment. Moreover, SR 41319 administration prevented the swelling from reaching its maximal value, and from day 24 to day 171 it was significantly less than in the positive controls (Fig. 1b). As shown in Table 1 treated rats had regained normal grip strength by day 170 . All

Table 1 Grip strength of arthritic rats. Effect of SR 41319 after three weeks of treatment

\begin{tabular}{|c|c|c|c|c|}
\hline \multirow[t]{2}{*}{ Group } & \multicolumn{2}{|l|}{ Day 35} & \multicolumn{2}{|l|}{ Day 170} \\
\hline & Number of rats & $\begin{array}{l}\text { Time on rotarod } \\
\text { (s) }\end{array}$ & Number of rats & $\begin{array}{l}\text { Time on rotarod } \\
(s)\end{array}$ \\
\hline Negative control & 5 & $24 \pm 6^{*}$ & 4 & $29 \pm 1$ \\
\hline Arthritic control & 7 & 0 & 7 & $7 \pm 4$ \\
\hline \multicolumn{5}{|l|}{ Arthritic + SR 41319} \\
\hline $0.16 \mathrm{mmo} / \mathrm{kg} / \mathrm{d}$ orally & 7 & $4 \pm 4$ & 6 & $28 \pm 2 \dagger$ \\
\hline
\end{tabular}

*Mean \pm SEM.

tp $\leqslant 0.02$ (treated versus arthritic controls, Student's $t$ test). 

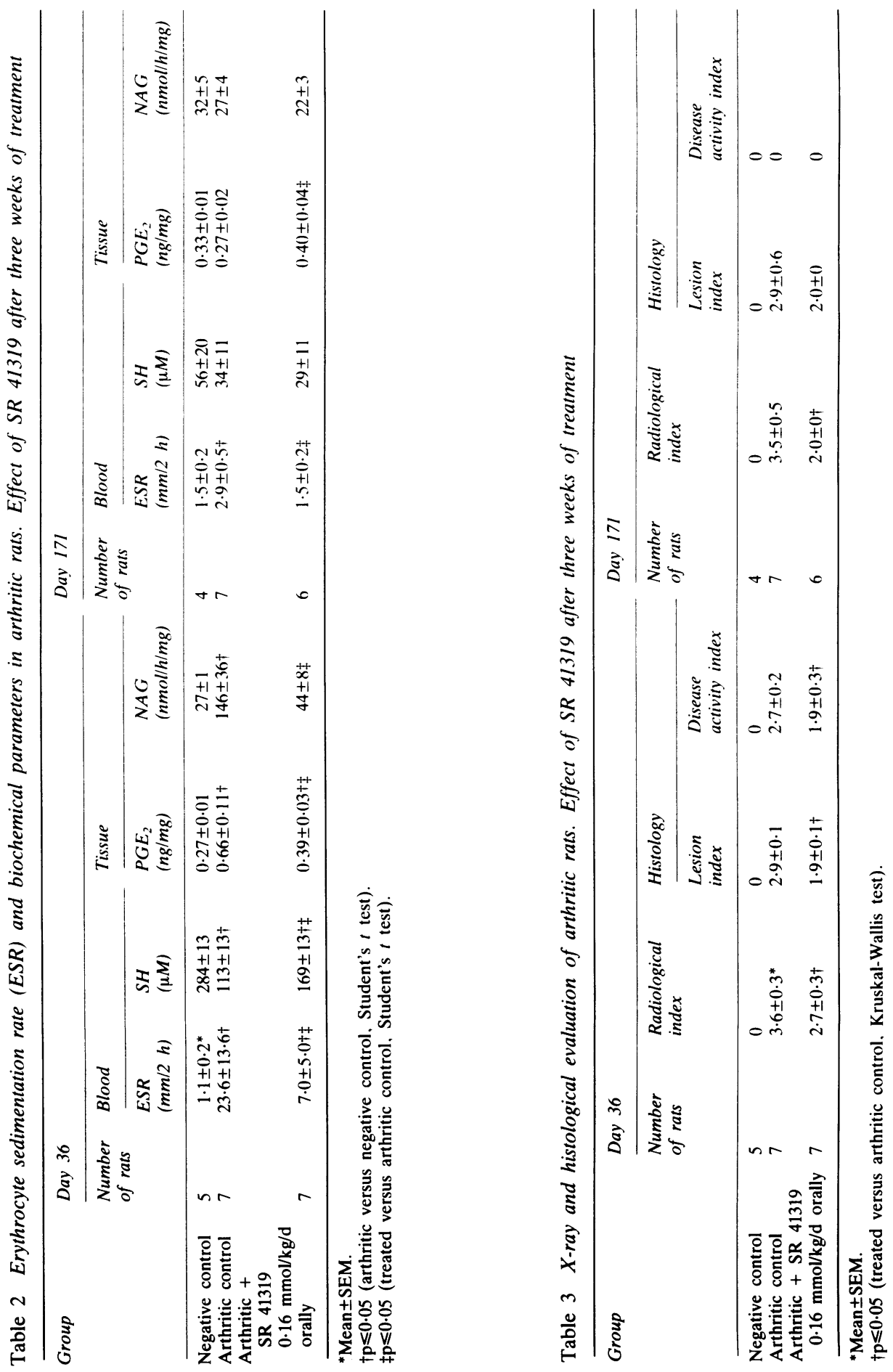


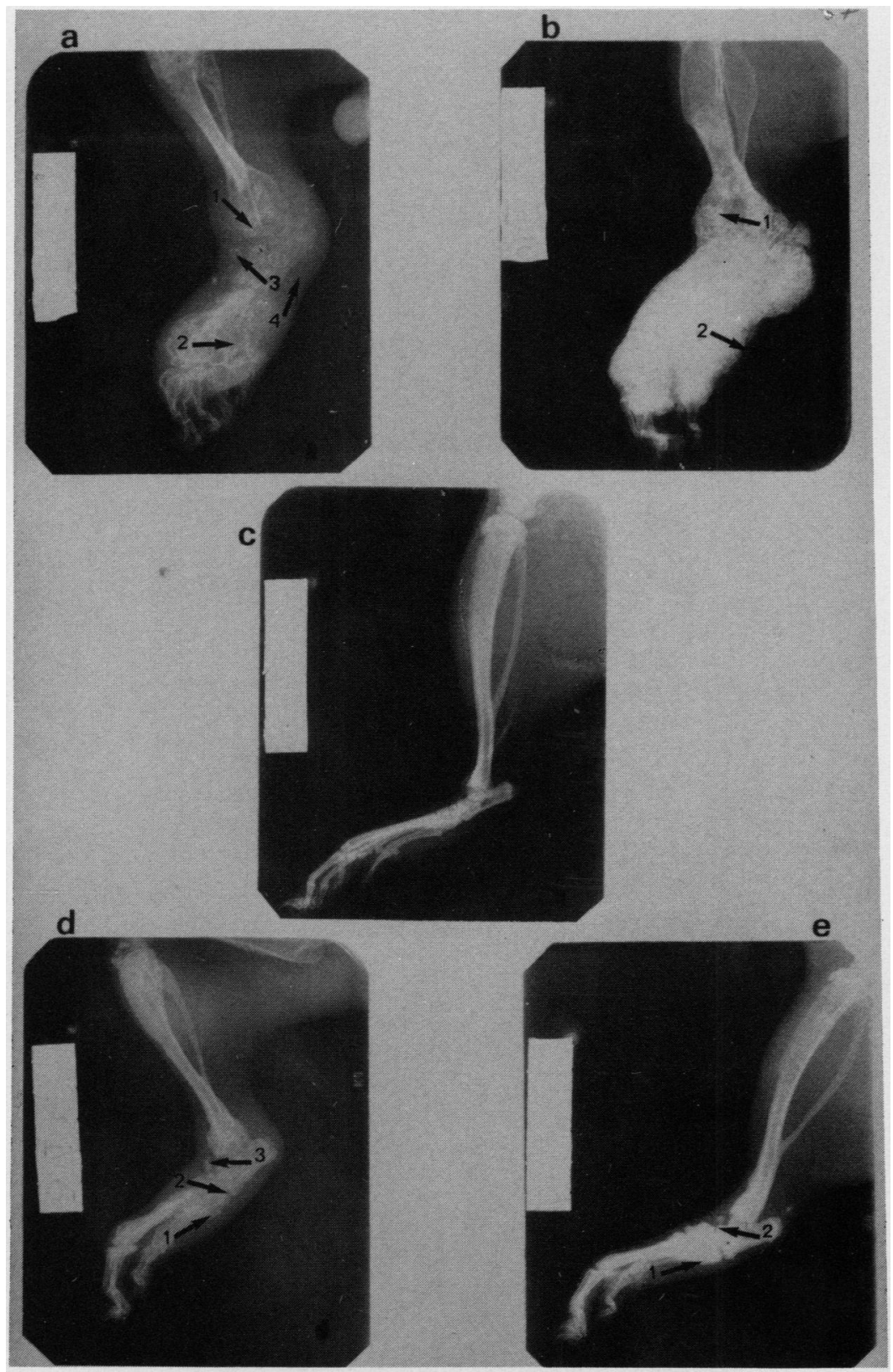

Fig. $2 X$-ray analysis. (a) Arthritic control: day 36. This rat hind limb shows bone enlargement with active osteophytosis, characterised by very thin trabeculae spreading from bone to connective tissue $(1 \rightarrow)$. This osteophytosis is marked on bone metaphysis and associated with lacunae $(2 \rightarrow)$. There are no visible joint spaces and some bone islets arise in the connective tissue $(3 \rightarrow)$, which is thickened and greatly enlarged $(4) . R I=3$. (b) Arthritic control: day 171. The normal structure of the hind limb is replaced by a large and lacunary asseous mass, with good delineated bone trabecula $(1 \rightarrow)$. The connective tissue is reduced and transparent $(2 \rightarrow) . R I=4$. (c) Negative control. No lesion. (d) Treated rat: day 36. There is early active osteophytosis in bone metaphysis $(1 \rightarrow)$ with reduced bone density, moderate alteration of joint spaces $(2 \rightarrow)$, and some bone islet formations $(3 \rightarrow)$ in a moderately enlarged and dense connective tissue. $R I=2$. (e) Treated rat: day 171 . Zones of minimal stabilised osteophytosis $(1 \rightarrow)$ (without newly formed trabecula) are visible in the bone metaphysis and there is persistence of minor joint space alterations $(2 \rightarrow) . R I=2$. 
72 Barbier, Brelière, Remandet, Roncucci
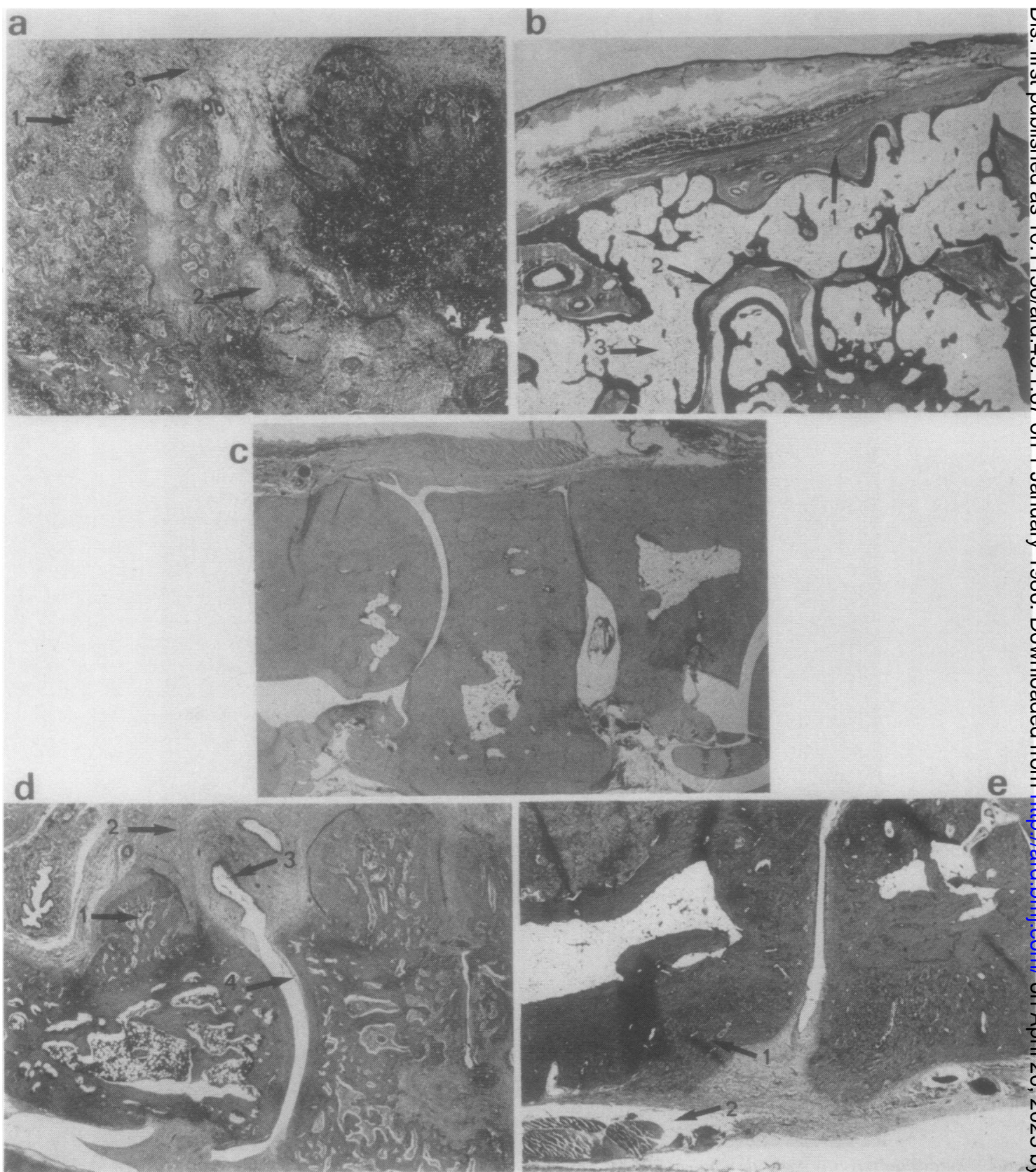

Fig. 3 Histological analysis. $(\times 20)$. (a) Arthritic control: day 36. No normal bone and joint structure. Marked cellular activity with intense osteolysis and osteogenesis $(1 \rightarrow)$. Some islets of chondrocytic activity are visible $(2 \rightarrow)$, and there is marked inflammatory cell infiltration of the connective tissue and of the bone marrow $(3 \rightarrow)$. LI=4;DAI=3. (b) Arthritic control: day 171. No normal bone and joint structure. No cellular activity. Fibrosis of the connective tissue $(1 \rightarrow)$, stability of bone trabecula $(2 \rightarrow)$, with no signs of osteogenesis or osteolysis. Bone marrow replaced by adipose tissue $(3 \rightarrow)$. LI=4; $D A I=0$. (c) Negative control. No lesion. (d) Treated rat: day 36. Osteophytosis in bone metaphysis spreading into diaphysis; minor alteration of joints characterised by minor fibrosis on articular surfaces. Moderate active osteophytosis $(l \rightarrow)$ in bone metaphysis, with newly formed bone trabeculae delineated by a dense osteoblastic cell margin; moderate inflammatory cell infiltration with some fibrosis of connective tissue $(2 \rightarrow)$, moderate synovitis $(3 \rightarrow)$, and minor fibrosis on articular surfaces $(4 \rightarrow) . L I=2 ; D A I=2$. (e) Treated rat: day 171 . Moderate osteophytosis; no joint lesion. Stabilised osteophytosis $(I \rightarrow)$; no cellular inflammatory cell infiltration of the connective tissue $(2 \rightarrow) . L I=2 ; D A I=0$. 
biochemical parameters in the treated group were significantly improved compared with controls on day 36 (Table 2). As expected, the same pattern was observed in the $x$-ray and histological analyses (Figs 2 and 3). On day 36 (Table 3) RI, LI, and DAI were significantly lower in the treated group than in the positive control group. On day 171 lesions were completely stabilised in both groups, but in SR 41319 treated rats they remained at a lower level, as assessed by both RI and LI (Table 3 ).

\section{Discussion}

Chronic disease, such as human rheumatoid arthritis or rat adjuvant arthritis (AA), involves not only obvious signs of inflammation but also changes in various haematological and biochemical parameters. ${ }^{6}$ According to Billingham and Davies ${ }^{7}$ there are two main methods for assessing adjuvant arthritis: (a) gross physical changes in affected joints and limbs and $(b)$ biochemical changes related to the systemic inflammatory response. Biochemical assessments of AA disease activity are frequently made, though their superiority over more traditional assessments of gross physical changes has been questioned. ${ }^{7}$ A previous study allowed us to show a close correlation between clinical and biochemical changes in the early acute phase of AA (day 0-day 32). ${ }^{8}$ Results reported in the present study show that this correlation does not persist for long: all the biochemical parameters were significantly abnormal on day 36 but had returned to normal values by day 171. Histological and $x$-ray examinations showed a similar evolution: after intense osteophytosis, osteolysis, and marked inflammatory cell infiltration on day 36 cellular activity had disappeared by day 171 , as indicated by the DAI. Maximal or near maximal values for the clinical parameters were reached on day 36 and remained at that level throughout the experiment. As shown in Figs $2 \mathrm{~b}$ and $3 \mathrm{~b}$ and confirmed by the LI irreversible articular and bone distortions could be detected as early as day 36 . Taken together, these findings suggest that: $(a)$ there is spontaneous resolution of the continuing (chronic) inflammation between day 36 and day 171; (b) during this period clinical parameters do not allow a clear distinction to be made between inflammation and arthritic lesions; $(c)$ by day 171 these parameters permit accurate evaluation of lesions; $(d)$ effects of drug treatment on cartilage and bone erosion should be assessed during the late stage of AA by clinical parameters.

Accordingly, the second part of the experiment was designed to show how a new pharmacological agent, orally administered during the early established phase of the disease, might influence the arthritic process by limiting cartilage and bone erosion as assessed in the late chronic phase of the disease. Previous studies of drug effects on AA have shown that NSAIDs and steroids are effective, but active disease generally reappears after discontinuing the treatment. ${ }^{6}$ Conflicting results have been obtained with the remission inducing drugs in clinical use, such as gold, levamisole, penicillamine, and chloroquine; in general, these substances are poorly effective in the model studied here. ${ }^{7}$ Diphosphonates have been reported to exert a beneficial effect on human rheumatoid arthritis, ${ }^{9}{ }^{10}$ and positive effects of hydroxy ethylidene diphosphonate (EHDP), dichloro methylene diphosphonate $\left(\mathrm{Cl}_{2} \mathrm{MDP}\right)$, and aminopropylidene diphosphonate (APD) on pathological bone resorption and on the inflammatory process in rat adjuvant arthritis have been shown after subcutaneous administration. ${ }^{11-14}$ It should be pointed out, however, that $(a)$ active disease reappeared at the end of three weeks of treatment with EHDP; ${ }^{11}$ (b) APD studies were limited to the early established phase of the disease ${ }^{1314}$ and $(c)$ when the late chronic phase was studied with $\mathrm{Cl}_{2} \mathrm{MDP}$ the drug was administered daily for eight weeks beginning on the mycobacterium injection day. ${ }^{12}$ In the present preliminary study we show that SR 41319, a new diphosphonate, orally administered at a dose of $0.16 \mathrm{mmol} / \mathrm{kg} /$ day between day 14 and day 35 postadjuvant, had major inhibitory effects on day 36 on inflammatory reactions and on associated tissue injury. On day 171 when inflammatory signs were no longer observed clinical parameters, radiological and histological lesion indexes were all significantly improved compared with controls.

From a structural point of view diphosphonates can be classified as: $(a)$ the hydroxylated diphosphonates like EHDP or APD, which have a tridentate binding potential to hydroxyapatite ${ }^{15}$ that is possibly involved in hydroxyapatite crystal growth inhibition in vitro and osteomalacia in vivo, and $(b)$ the non-hydroxylated diphosphonates like $\mathrm{Cl}_{2} \mathrm{MDP}$ with only bidentate binding potential and thus a lower binding energy, which may account for their lack of interference with bone formation. ${ }^{16} \mathrm{SR}$ 41319 belongs to the second group, and in a model of in-vivo experimental calcification SR 41319, unlike EHDP, does not impair calcification, ${ }^{17}$ though it inhibits bone resorption both in vitro ${ }^{18}$ and in vivo in a model of osteopenia induced by castration in male rats. ${ }^{19}$ However, it is unlikely that the powerful effects of diphosphonates are due only to their physicochemical effects on hydroxyapatite dissolution; indeed, diphosphonates have powerful cellular $^{20}$ and immunological ${ }^{21-23}$ effects. SR 41319 inhibits some of the activities of interleukin I, 
especially the secretion of neutral protease and collagenase by synovial cells and chondrocytes, and also the blastic transformation of $\mathrm{T}$ lymphocytes stimulated by mitogens. ${ }^{24}$

If the fact that interleukin I has been detected in rheumatoid joint effusions ${ }^{25}$ and probably also in serum from patients with active rheumatoid arthritis $^{26}$ is taken into account, this inhibitory effect of SR 41319 on the effects of interleukin I may at least partly explain its antiarthritic activity.

We are grateful to Mrs A M Brunel. J Gimenez. C Planchenault, $M$ Richard, and $C$ Vernhet for their skilled technical assistance. We thank Miss C Garnero for typing this manuscript.

\section{References}

1 Dudley-Hart F. Huskisson E C. Non-steroidal anti-inflammatory drugs. Current status and rational therapeutic use. Drugs 1984: 27: 232-55.

2 Brelière J C. Emonds-Alt X. Garcia G. Eur Patent Appl 1984; EP100: 178

3 Butler M. Giannina T. Cargill D I. Popick F. Steinetz B G. Abnormal sulfhydryl-disulfide interchange in serum of rats with adjuvant arthritis: correction by anti-inflammatory agents. Proc Soc Exp Biol Med 1969: 132: 484-8.

4 Dray F. Charbonnel B. Maclouf J. Radioimmunoassay of prostaglandins $F . E_{1}$, and $E_{2}$ in human plasma. Eur J Clin Invest 1975; 5: 311-8.

5 Vaes G, Jacques P. Studies on bone enzymes: the assay of acid hydrolases and other enzymes in bone tissue. Biochem $J 1965$; 97: $380-8$

6 Owen R T. Adjuvant induced polyarthritis. An overview. Methods Find Exp Clin Pharmacol 1980: 2: 199-204.

7 Billingham M E. Davies G E. Experimental models of arthritis in animals as screening tests for drugs to treat arthritis in man. In: Vane J R. Ferreira S H. eds. Anti-inflammatory drugs. Berlin/Heidelberg/New York: Springer, 1979: 108-44.

8 Barbier A. Navarro J. Brelière J C. Roncucci R. Biochemical and clinical changes in rats with developing adjuvant arthritis. Agents Actions 1984: 15: 103-5.

9 Bijvoet O L M. Frijlink W B, Jie K, et al. APD in Paget's disease of bone. Arthritis Rheum 1980; 23: 1193-204.

10 Van Paassen H C, Mallee C, de Vries E, et al. The effect of the biphosphonate APD in rheumatoid arthritis. European Congress of Rheumatology. Moscow 1983.

11 Francis M D. Flora L, King W R. The effects of disodium ethane-1-hydroxy-1,1-diphosphonate on adjuvant induced arthritis in rats. Calcif Tissue Res 1972; 9: 109-21.

12 Flora L. Comparative anti-inflammatory and bone protective effects of two diphosphonates in adjuvant arthritis. Arthritis Rheum 1979; 22: 340-6.
13 Glatt M. Blatter A. Bisping M. Bray M A. Effects of diphosphonates (APD. EHDP) on inflammation and bone $\vec{\nexists}$ turnover in adjuvant arthritis rats. Experientia 1983: 39: 681.

14 Kong A S. Shao J, Rappo R, Leibowitz M. Effects ofo diphosphonates (DPs) on rat adjuvant arthritis (AA). The $\frac{\bar{\sigma}}{\sigma}$ Second International Conference on Immunopharmacology, Washington, 1982.

15 Barnett B L, Strickland L C. Structure of disodium dihydrogen 1-hydroxyethylene diphosphonate tetrahydrate: a bone growth regulator. Acta Cryst 1979; B35: 1212-4

16 Francis M D. Davis T L. Benedict J J, Tofe A J. Diphosphon- $\vec{\circ}$ ates: in vitro absorption and desorption studies on hydroxyapatite and diffusion in bone. In: Caniggia A. ed. Proceedings of the $\overrightarrow{\vec{\omega}}$ 1st International Symposium on Diphosphonates in Therapy, Rome, 1979.

17 Barbier A. Brelière J C. Roncucci R. Altered hydroxyapatite crystal deposition in arthritic rats: The effect of SR 41319. a new i diphosphonate. IUPHAR 9th International Congress of Phar-? macology, London 1984.

18 Emonds-Alt X. Brelière J C. Roncucci R. Effects of SR 41319 on the in vitro bone resorption. XVIth International Congress of 0 Rheumatology, Sydney 1985.

19 Barbier A. Emonds-Alt X. Brelière J C. Roncucci R. Effect of SR 41319, a new diphosphonate, on castration-mediatedo osteopenia in the old male rat: a biochemical study. XVIth International Congress of Rheumatology. Sydney 1985.

20 Fast D K. Felix R. Dowse C. Neuman W F. Fleisch H. The effects of diphosphonates on the growth and glycolysis of $\overrightarrow{0}$ connective tissue cells in culture. Biochem J 1978: 172: 97-107.\%

21 De Vries E. Van Der Weij J P. Van Der Veen C J P. et al. In vitro effect of (3-amino-1-hydroxy propylidene)-1,1-ס biphosphonic acid (APD) on the function of mononuclear phagocytes in lymphocyte proliferation. Immunology 1982; 47: 157-63.

22 Labat M L. Florentin I, Davigny M. Moricard Y. Milhaud G.̊ำ Dichloromethylene diphosphonate $\left(\mathrm{Cl}_{2} \mathrm{MDP}\right)$ reduces natural killer (NK) cell activity in mice. Metab Bone Dis Relat Res $\underset{\vec{\Phi}}{\overrightarrow{2}}$ 1984: 5: 281-7.

23 Milhaud G, Labat M L, Moricard Y. (Dichloromethylene) diphosphonate-induced impairment of T-lymphocyte function. Proc Natl Acad Sci USA 1983; 80: 4469-73.

24 Roncucci R. Barbier A. Brelière J C. Emonds-Alt X. Recent advances in the field of remission-inducing drugs for arthritis. Proceedings of the IIIrd International Congress of Inflammation. Paris 1984.

25 Nouri A M E, Panayi G S. Goodman S M. Cytokines and the chronic inflammation of rheumatic disease. I. The presence of interleukin I in synovial fluids. Clin Exp Immunol 1984; 55? 295-301.

26 Tan P. Shore A. Leary P. Keystone E C. Interleukin abnormalities in recently active rheumatoid arthritis. $J$ Rheuma tol 1984; 5: 593-6. 